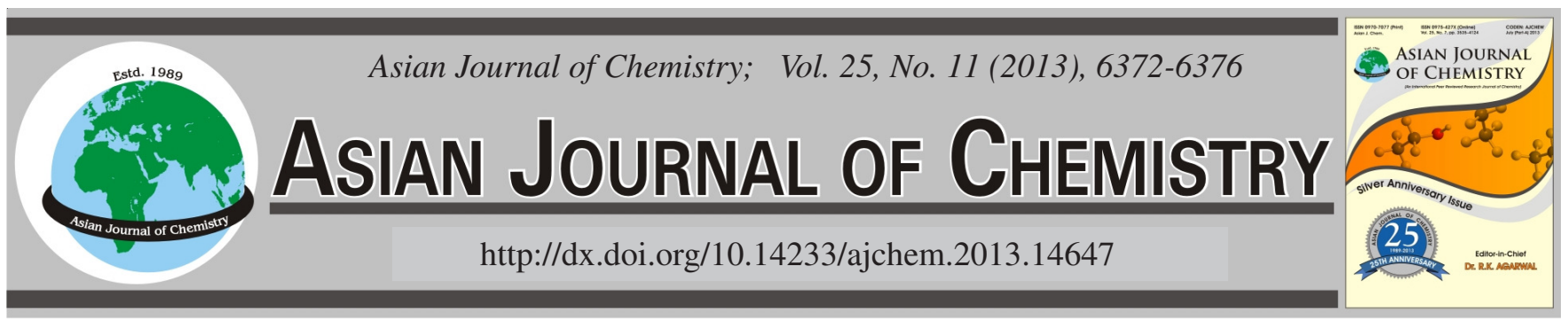

\title{
Chemical Compositions of Essential Oils of Different Parts and Extract of Achillea santolina L. from Iran
}

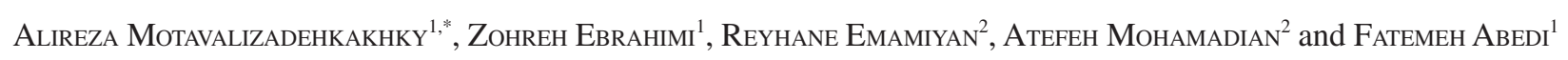

${ }^{1}$ Department of Chemistry, Neyshabur Branch, Islamic Azad University, Neyshabur, Iran

${ }^{2}$ Research and Development (R \& D) Center, Shadgole Khorasan Factory, Neyshabur, Iran

*Corresponding author: Tel: +98 9153510342; E-mail: amotavalizadeh@yahoo.com

(Received: 3 October 2012;

Accepted: 10 May 2013)

AJC-13475

GC and GC-MS analysis of the isolated essential oils obtained by steam distillation from the flowers, leaves and stem of Achillea santolina L., known to have medicinal activity, collected from Iran. The constituents obtained by hexane-ether extraction of the aerial parts of Achillea santolina $\mathrm{L}$. resulted in the identification of 48-59 constituents (96.1-98.0\% of the total oils and extract). Different parts of $A$. santolina were the valuable organs for the essential oil production representing a yield of $0.15-0.7 \%$ (w/w). In the hydrodistilled oil of three parts and the extract of A. santolina, 1,8-cineole (3-5 \%), camphor (3.8-5.1\%), terpinene-4-ol (4.0-7.1\%), fragranol (7.1-9.1\%), fragranyl acetate (20-37\%), $\alpha$-terpinyl acetate (0.6-5.1\%), caryophyllene oxide (1.2-3.2 \%), $\alpha$-muurolol (1.1-3.6 \%) and some alkanes, alkanoic acids and esters were principle components, also monoterpenes (7.1-9.1\%) and oxygenated monoterpenes (55.1-77.2 \%) were dominant components.

Key Words: Achillea santolina L., Essential oil composition, Solvent extract, Fragranyl acetate.

\section{INTRODUCTION}

The genus Achillea $\mathrm{L}$. (Asteraceae) is represented by about 115 species found in the northern hemisphere, mostly in Europe and Asia and commonly known as yarrows ${ }^{1-3}$. It has been represented in Iran by nineteen species including seven endemics, among this genus, Achillea santolina L. (it has been known as Bomadaran in Iran) is represented in Iran $^{4}$. The Achillea L. species belong to the oldest medicinal plants that are used both for pharmaceutical purposes and in folk medicine.

These plants contain a complex of different pharmacological compounds, for example, terpenes, flavonoids, alkaloids, bitters, tannins, lignans ${ }^{5}$.

Achillea species are diuretic, emmenagog agents, wound healing, for curing stomachache, diarrhea and antichloristic, antispasmodic, antiseptic and infection preventing properties and have been used to reduce sweating and to stop bleeding, amarum, stomachicum, cholagolum and carminativum, too ${ }^{3,6-13}$. The Achillea genus has a wide distributional range $\mathrm{e}^{14}$ and the differences in oil composition may be affected by different environmental factors, plant genetic type, seasonality and developmental stage, because of a chemically polymorphic and perennial ${ }^{15}$.

Terpenoids (1,8-cineole, camphor, borneol, pinenes, artemisia ketone, santolina alcohol, farnesane, caryophyllene and its oxides, cubebene, germacrenes, eudesmol, $\alpha$-bisabolol and oxides, farnesene, $\gamma$-gurjunene, $\gamma$-muurolene and chamazulene) are the principle components of Achillea essential oils ${ }^{3,13}$

Chemical composition of the essential oils of five Achillea species from Turkey ${ }^{6}$, also essential oils and hexane extracts of A. frarantissima and A. santolina from Egypt ${ }^{16}$, composition at different development stages of the essential oil of four Achillea species grown in $\operatorname{Iran}^{17}$ and composition of the essential oil of A. wilhelmsii collected from Kazeroon in Fars province, $\operatorname{Iran}^{18}$ were established by GC/MS and GC. There are few reports about essential oil composition of $A$. santolina compared with another Achillea genus ${ }^{19,20}$. In the present study, the flowers, leaves and stems of the Achillea santolina L. collected from Khorasan Razavi province, Iran, were investigated for their essential oil compositions as well as hexaneether extract, which analyzed by both gas chromatography and gas chromatography mass spectrometry.

\section{EXPERIMENTAL}

Achillea santolina L. was collected from Jannatabad (latitude $+35^{\circ} 35^{\prime} 56.30^{\prime \prime} \mathrm{N}$, longitude $+61^{\circ} 8^{\prime} 25.97 " \mathrm{E}$ ) in Torbat Jam, Khorasan-Razavi Province, Iran, in June 2011. The plant was air dried and dried sample was crushed, then essential oils were obtained by hydrodistillation (HD) of their flowers, 
leaves and stem, separately. Aerial part of plant for extract was dried and crushed. Voucher specimens of the plant have been deposited in the Ferdowsi University of Mashhad herbarium (FUMH), Mashhad, Iran, by Prof. Javad Ghoreishalhosseini.

Sample preparation: The flowers, leaves and stems of A. santolina L. were separately subjected to hydrodistillation for $4 \mathrm{~h}$ using an original Clevenger-type apparatus and yielded essential oils from 0.15 to $0.7 \%$ (w/w) of dry matters. After decanting, the obtained essential oils were dried over anhydrous sodium sulfate and after filtration, stored in refrige-rator at $-4{ }^{\circ} \mathrm{C}$ until tested and analyzed.

For extract preparation, the aerial parts of plant ( $c a .50 \mathrm{~g}$ ) were shaken sequentially in percolation with hexane-ether $(1: 1$, $\mathrm{v} / \mathrm{v})$ for $16 \mathrm{~h}(15 \mathrm{~mL} / \mathrm{g})$ at room temperature. Sample was sonicated for $15 \mathrm{~min}$ twice and then solvents were removed subsequently under reduced pressure by rotary evaporator apparatus. The extract was weighed and stored in refrigerator at $4{ }^{\circ} \mathrm{C}$ until tested; the yield was $1.2 \%$ (Table- 1 ).

\begin{tabular}{lccc}
\multicolumn{4}{c}{ TABLE-1 } \\
WEIGHT OF DIFFERENT PARTS OF PLANT, TIME \\
\multicolumn{4}{c}{ AND YIELD (\%) OF HYDRODISTILLATION (HD) } \\
\hline \multicolumn{1}{c}{ Parameter } & $\begin{array}{c}\text { Weight (g) out of } \\
\text { dry matter }\end{array}$ & $\begin{array}{c}\text { Time } \\
(\mathrm{h})\end{array}$ & $\begin{array}{c}\text { Yield } \\
(\%)\end{array}$ \\
\hline Flower oil & 110 & 4 & 0.70 \\
Leaf oil & 125 & 4 & 0.25 \\
Stem oil & 107 & 4 & 0.15 \\
Hexane-ether extract & 50 & 16 & 1.20 \\
\hline
\end{tabular}

Gas chromatography: The essential oils were diluted $(1 / 100$ in hexane, v/v) and $1 \mu \mathrm{L}$ were injected manually and in the splitless mode were used for analysis. GC-MS analyses of the essential oils and extracts was analyzed on an Agilent Technologies 7890A GC system coupled to a 5975C VLMSD mass spectrometer with an injector 7683B series device. An Agilent (9091) 413:325 ${ }^{\circ} \mathrm{C}$, HP-5 column $(30 \mathrm{~m} \times 320 \mu \mathrm{m} \times$ $0.25 \mu \mathrm{m}$ ) was used with helium as carrier gas at a flow rate of $3.35 \mathrm{~mL} / \mathrm{min}$. The GC oven temperature was initially programmed at $50{ }^{\circ} \mathrm{C}$ (hold for $1 \mathrm{~min}$ ) and finally at $300{ }^{\circ} \mathrm{C}$ (hold for $5 \mathrm{~min}$ ) at a rate of $8^{\circ} \mathrm{C} / \mathrm{min}$ while the trial temperature was $37.25^{\circ} \mathrm{C}$.

The column heater was set at $250^{\circ} \mathrm{C}$ in a splitless mode while the pressure was 10.2 psi with an average velocity of $66.5 \mathrm{~cm} / \mathrm{s}$ and a hold-up time of $0.75 \mathrm{~min}$. Mass spectrometry was run in the electron impact mode (EI) at $70 \mathrm{eV}$. The percentage compositions were obtained from electronic integration measurements using flame ionization detector (FID), set at $250{ }^{\circ} \mathrm{C}$.

Gas chromatography-mass spectrometry: The essential oils and extract were analyzed by GC-MS on an Agilent Technologies 7890A GC system coupled to a 5975C VLMSD mass spectrometer with an injector 7683B series device. An Agilent (9091) 413:325 ${ }^{\circ} \mathrm{C}$, HP-5 column $(30 \mathrm{~m} \times 320 \mu \mathrm{m} \times$ $0.25 \mu \mathrm{m}$ ) was used with helium as carrier gas at a flow rate of $3.35 \mathrm{~mL} / \mathrm{min}$. GC oven temperature and conditions were as described above. The injector temperature was at $250^{\circ} \mathrm{C}$. Mass spectra were recorded at $70 \mathrm{eV}$. Mass range was from $\mathrm{m} / \mathrm{z} 30$ to 500. Diluted samples (1/100 in hexane, v/v) of $1 \mu \mathrm{L}$ were injected manually and in the splitless mode.
Detection method: The identification of the components were based on their retention indices data determined by reference to a homologous series of $n$-alkenes $\left(\mathrm{C}_{9}-\mathrm{C}_{28}\right)$ and by comparison of their mass spectral fragmentation patterns with those of authentic compounds or with data published in the literature as described by Adams ${ }^{21}$. Further identification was made by matching their recorded mass spectra with those stored on the MS library (NIST 08.L database/chemstation data system). Determination of the percentage composition was based on peak area normalization without using correction factors.

\section{RESULTS AND DISCUSSION}

Essential oils and extract composition: The essential oil were obtained from the crushed flowers, leaves and stems by separately hydrodistillation. The hexane-ether extract was obtained from aerial parts of $A$. santolina, which were immediately analyzed by both gas chromatography and gas chromatography-mass spectrometry system. The results are presented in Table-2.

A total of 53, 48 and 50 chemical constituents, representing 96.1, 98.0 and $96.3 \%$ of the total content, were identified in each investigated essential oils isolated from flower, leaf and stem, respectively. $50 \mathrm{~g}$ out of aerial parts extracted by a mixture (1:1) of hexane-ether followed by GC and GC-MS analysis, $59(97.2 \%)$ components were characterized. In addition, the essential oils were also found to be rich in oxygenated monoterpenes $(>72 \%)$, while solvent extract showed minor amount $(55.1 \%)$. In essential oils monoterpenes (8.3-9.1\%), sesquiterpenes (3.0-4.7\%) and oxygenated sesquiterpenes (5.2-7.4\%) were less. Hexane-ether extract of A. santolina showed $7.1 \%$ monoterpene hydrocarbon, $4.5 \%$ sesquiterpene hydrocarbon, $14.1 \%$ oxygenated sesquiterpene and $16.5 \%$ non-terpene compounds. 1,8-cineole (3.0-5.0\%), Z-sabinene hydrate (2.1$3.5 \%$ ), camphor (3.8-5.1\%), terpinen-4-ol (4.0-7.1\%), fragranol (7.1-9.1\%), fragranyl acetate $(20.0-37.0 \%), \alpha$-terpinyl acetate (0.6-5.1\%), caryophyllene oxide (1.2-3.2\%), $\alpha$-muurolol (1.1$3.6 \%)$ and some alkanes, alkanoic acids and esters were major components in oils and solvent extract. Hexadecanoic acid $(5.2 \%)$, eicosane $(4.2 \%)$ and methyl linoleate $(3.1 \%)$ only investigated in hexane-ether extract.

Essential oils of flower, leave and stem of A. santolina from Egyptian plant have been studied and 44 (97.62\%), 43 (95.62\%) and $37(96.09 \%)$ compounds identified respectively. Fragranyl acetate (45-52\%), fragranol (11-19\%), borneol (3-5\%), terpin-4-ol (6-7 \%) and camphor (3-4\%) were the main constituents in the investigated parts ${ }^{16}$. The principle components in the hexane-ether extract of the aerial parts were fragranyl acetate $(50.7 \%)$, fragranol $(8.78 \%)$ and camphor $(6.6 \%)$. Mainly oxygenated monoterpenes were identified as the major constituents. Some constituents were observed in same amounts and were in agreement with our finding, but some constituents were identified by different percentages.

In A. santolina from Jordan, terpenoids (1,8-cineole, camphor, bomeol, pinenes, artemisia ketone, santolina alcohol, farnesane, caryophyllene and its oxides, $\alpha$-bisabolol and oxides, cubebene, germacrenes, eudesmol, farnesene, $\gamma$-gurjunene, $\gamma$-muurolene and chamazulene) are the principle 
CHEMICAL COMPOSITION $\left(\%^{\mathrm{a}}\right)$ OF THE ESSENTIAL OILS OF FLOWERS, LEAVES AND STEMS, AND HEXANE-ETHER EXTRACT OF AERIAL PARTS ISOLATED FROM A. santolina IDENTIFIED BY KI ${ }^{\mathrm{b}}$ AND GC-MS ${ }^{\mathrm{c}}$

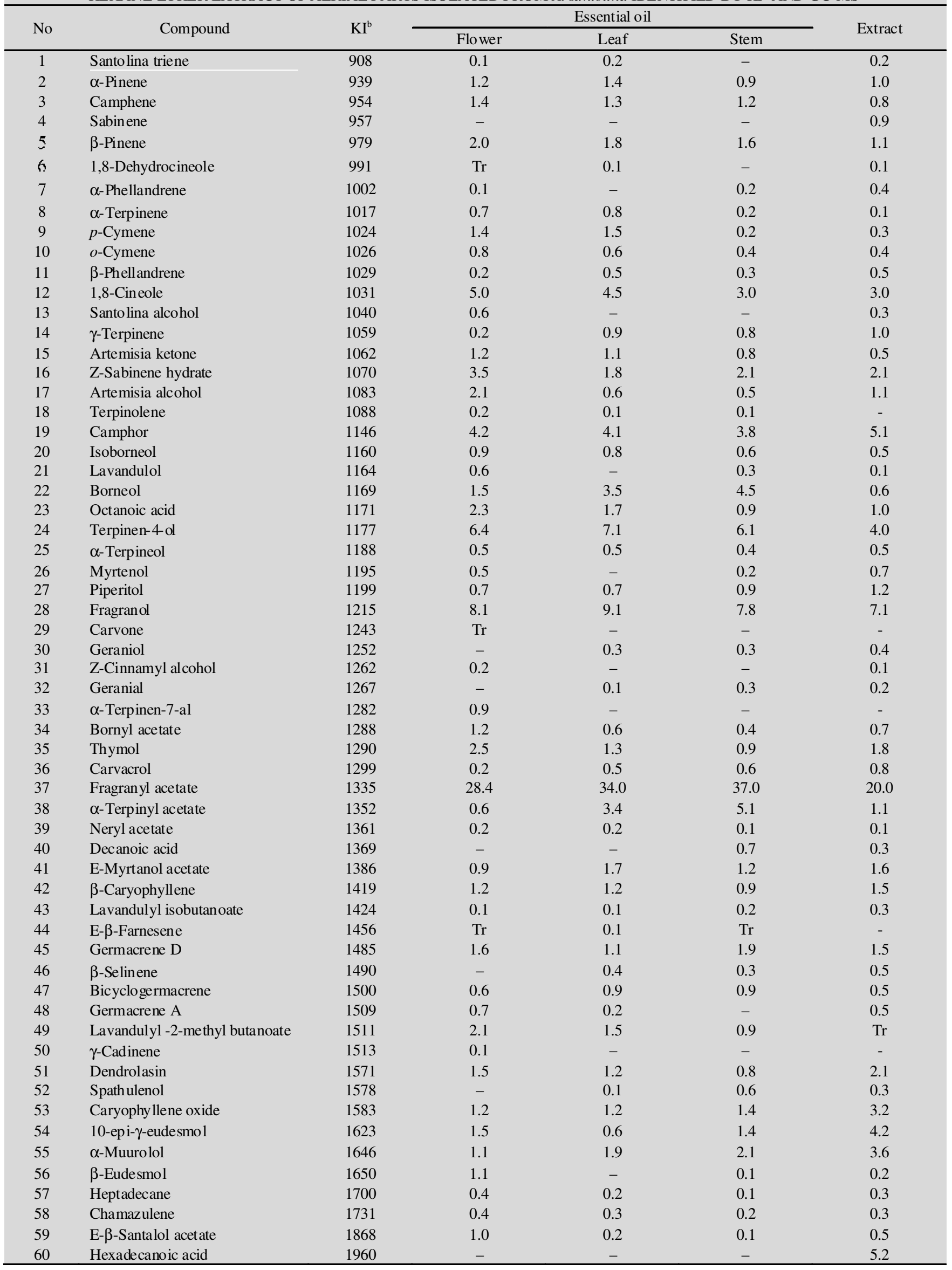




\begin{tabular}{|c|c|c|c|c|c|c|}
\hline 61 & $n$-Eicosane & 2000 & - & - & - & 4.2 \\
\hline 62 & Methyl linoleate & 2085 & - & - & - & 3.1 \\
\hline 63 & n-Heneicosane & 2100 & - & - & - & 1.5 \\
\hline 64 & $n$-Tricosane & 2300 & - & - & - & 1.5 \\
\hline \multicolumn{3}{|c|}{ Number of identified compounds } & 53 & 48 & 50 & 59 \\
\hline \multicolumn{3}{|c|}{ Yield of the oil \% } & 0.7 & 0.25 & 0.15 & 1.2 \\
\hline \multicolumn{3}{|c|}{ Monoterpene hydrocarbons } & 8.3 & 9.1 & 8.9 & 7.1 \\
\hline \multicolumn{3}{|c|}{ Sesquiterpene hydrocarbons } & 4.7 & 4.3 & 3.0 & 4.5 \\
\hline \multicolumn{3}{|c|}{ Oxygenated sesquiterpenes } & 7.4 & 5.2 & 6.5 & 14.1 \\
\hline \multicolumn{3}{|c|}{ Others } & 3.3 & 2.2 & 1.9 & 16.5 \\
\hline \multicolumn{3}{|c|}{ Total identified } & 96.1 & 98.0 & 96.3 & 97.2 \\
\hline
\end{tabular}

components $^{22}$. The variations of the essential oil content and morphological values in ten accessions of $A$. santolina were collected from northwestern of Iran, have been investigated ${ }^{23}$. Two genotypes which were gathered from Lorestan and Kurdistan provinces, respectively, the highest mean of essential oil content ( 0.2 and $0.19 \%$, respectively). Considering the amount of essential oil in each genotype from each province, they have been mentioned that this feature varied with location with western Iran having the highest.

Essential oil variation among and within six Achillea species transferred from different ecological regions in Iran to the field conditions investigated ${ }^{24}$. According to the major compounds, four chemotypes were defined. Among them four A. santolina collected from Natanz, Malayer, Arak and Yasooj in center and west of Iran, were studied. Their yield essential oils were between 0.1-0.6\% and 43 components identified. comphor, borneol, bornyl acetate, germacrene $\mathrm{D}$ and spathulenol were major constituents.

In another experimental study, yarrow plant in late spring was collected from Sistan region, east of Iran, in 2008. The compounds of the essential oil were analyzed by GC/MS. In this study, camphor was the major compound of the essential oil $^{25}$.

According to Nemeth ${ }^{26}$, studies within the last 15 years, an average of 54 compounds have been identified in different species. Among them, the largest numbers of components (149 compounds) were found in the oils of some Achillea species. 1,8 -cineole, camphor, borneol, $\alpha$-/ $\beta$-pinenes are among the five most abundant monoterpene components. Among the monoterpenes, 1,8-cineole is major component in Achillea species $^{27-29}$. In some Achillea species essential oil components, camphor and borneol are next ranks ${ }^{30-33}$. The previous studies reported that the major constituents of A. tenuifolia were $\gamma$-muurolene ${ }^{34}$, limonene ${ }^{35}$ and camphor ${ }^{33,36,37}$.

Chamazulene, $\beta$-caryophyllene and oxide, eudesmol, $\alpha$-bisabolol as well as its oxides and farnesene are the most frequently sesquiterpene constituents ${ }^{26} .1,8$-Cineole, camphor, piperitone and ascaridole have reported by some researchers as the major constituent in several Achillea species in Turkey ${ }^{32,38-40}$.

\section{Conclusion}

It could be concluded that difference in the essential oils and extract composition of $A$. santolina influenced by ecological conditions and type of the organ in which essential oil was produced and solvent that is used for extraction. The results of this study revealed the importance of comparing and exploring the variance of essential oils and extracts composition, from different parts of A. santolina, since this heterogeneous repartition of bioactive substances and classes of compounds between flower, leaf, stem and extracts entrained the variability of their potential antimicrobial activities.

\section{ACKNOWLEDGEMENTS}

The authors thank Prof. Abdolhusain Rustaiyan, Dr. Shiva Masoudi and Mr. Mojtaba Sakkaki for useful suggestions.

\section{REFERENCES}

1. N.S. Radulovic, P.D. Blagojevic, D. Skropeta, A.R. Zarubica, B.K. Zlatkovic and R.M. Palic, Nat. Prod. Commun., 5, 121 (2010).

2. B. Benedek, K. Rothwangl-Wiltschnigg, E. Rozema, N. Gjoncaj, G. Reznicek, J. Jurenitsch, B. Kopp and S. Glasl, Pharmazie, 63, 23 (2008).

3. E. Nemeth and J. Bernath, Curr. Pharm. Design, 14, 3151 (2008).

4. V. Mozaffarian, A Dictionary of Iranian Plant Names, Farhang Moaser Publishers, Tehran, Iran (2007).

5. T. Aburjai and M. Hudaib, Pharmacog Mag, 2, 191 (2006).

6. O. Toncer, S. Basbag, S. Karaman, E. Diraz and M. Basbag, Int. J. Agric. Biol., 12, 527 (2010).

7. A. DerMarderosian, The Review of Natural Products, Facts and Comparison press, Missouri, p. 636 (2001).

8. E. Yesilada, G. Honda, E. Sezik, M. Tabata, K. Goto and Y. Ikeshiro, J. Ethnopharmacol., 39, 31 (1993).

9. T. Baytop, Phytotherapy in Turkey, Nobel T.P. Kitabevleri Ltd., Sti., Istanbul, Tureky, edn. 2 (1995).

10. S. Konyalioglu and C. Karamenderes, J. Ethnopharmacol., 102, 221 (2005).

11. J. Hubik, Obecná farmakognosie (II. díl)-Sekundární látky, Praha, p. 275 (1978).

12. U. Kastner, S. Sosa, M. Wolf, A. Tubaro, J. Jurenitsch and D.R. Loggia, Sci. Pharm., 61, 47 (1993).

13. X.T. Si, M.L. Zhang, Q.W. Shi and H. Kiyota, Chem. Biodivers, 3, 1163 (2006).

14. N. Celik and H.A. Akpulat, Kew Bull., 63, 485 (2008).

15. N. Bezic, M. Skocibucic, V. Dunkic and A. Radonic, Phytother. Res., 17, 1037 (2003).

16. A.M. El-Shazly, S.S. Hafez and M. Wink, Pharmazie, 59, 226 (2004).

17. M. Azizi, R. Chizzola, A. Ghani and F. Oroojalian, Nat. Prod. Commun., 5, 283 (2010).

18. K. Javidnia, R. Miri and H. Sadeghpour, Daru, 12, 63 (2004).

19. S.M. Khafagy and L. El-Faraty, J. Pharm. Sci. (UAR), 11, 239 (1970).

20. S. Afsharypour, S. Asgary and G.B. Lockwood, Planta Med., 62, 77 (1996).

21. R.P. Adams, Identification of Essential Oil Components by Gas Chromatography/Mass Spectrometry, Allured Publishing Co. Carol Stream, Illinois, edn. 4 (2007). 
22. A. Bader, G. Flamini, P.L. Cioni and I. Morelli, Flavour Frag. J., 18, 36 (2003).

23. M. Farajpour, M. Ebrahimi, R. Amiri, S.A. Sadat Nori and R. Golzari, J. Med. Plant Res., 5, 4393 (2011).

24. M. Rahimmalek, B.E. Sayed Tabatabaei, N. Etemadi, S.A.H. Goli, A. Arzani and H. Zeinali, Ind. Crop Prod., 29, 348 (2009).

25. Z. Ahmadi, M. Sattari, B. Tabaraee and M. Bigdeli, Arak Med. Univ. J., 14, 1 (2011)

26. E. Nemeth, J. Essent Oil Res., 17, 501 (2005).

27. Z. Toker, H.C. Ozen, R.A. Clery and N.E. Owen, J. Essent Oil Res., 15, 100 (2003).

28. M. Unlu, D. Daferera, E. Donmez, M. Polissiou, B. Tepe and A. Sokmen, J. Ethnopharmacol., 83, 117 (2002).

29. A. Kowalczuk, J. Dabrowska and A. Nosal, Herba Pol., 44, 114 (1998).

30. P. Magiatis, A.L. Skaltsounis, I. Chinou and S.A. Haroutounian, Z. Naturforsch, 57C, 287 (2002).

31. A. Feizbakhs, M.S. Tehrani and A. Rustaiyan, J. Essent. Oil Res., 15 21 (2003).
32. H.C. Ozen, Z. Toker, R.A. Clery and N.E. Owen, J. Essent. Oil Res., 15, 96 (2003).

33. A. Rustaiyan, H. Komeilizadeh, M.S. Shariatpanahi, A. Jassbi and S. Masoudi, J. Essent. Oil Res., 10, 207 (1998).

34. K. Jaimand and M.B. Rezaee, J. Essent. Oil Res., 13, 354 (2001).

35. A. Shafaghat, J. Med. Plants, 8, 93 (2009).

36. A. Rustaiyan, F. Mojab, S. Masudi and M. Yari, Iran. J. Chem. Eng., 18, 108 (1999).

37. Z. Aghjani, S. Masoudi and A. Rustaiyan, J. Essent. Oil Res., 12, 723 (2000).

38. S. Kusmenoglu, K.H.C. Baser, T. Ozek, M. Harmandar and Z. Gokalp, J. Essent. Oil Res., 7, 527 (1995).

39. O. Baris, M. Gulluce, F. Sahin, H. Ozer, H. Kilic, H. Ozkan, M. Sokmen and O. Ozbek, Turk. J. Biol., 30, 65 (2006).

40. S. Kordali, A. Cakir, T.A. Akcin, E. Mete, A. Akcin, T. Aydin and H. Kilic, Crops Prod., 29, 562 (2009). 